\title{
Increased cell membrane arachidonic acid in experimental colorectal tumours
}

\author{
M L Nicholson, J P Neoptolemos, H A Clayton, I C Talbot, P R F Bell
}

\begin{abstract}
Tumour cell membrane fatty acid composition was investigated using an animal model of colorectal carcinogenesis. Eighty six male Wistar rats were fed experimental diets containing either $5 \%$ saturated fat or $20 \%$ saturated fat. Colorectal tumours were induced by intraperitoneal injection of azoxymethane, and control rats received saline. Animals were killed at intervals up to 26 weeks after the last injection of carcinogen for histology and lipid analysis. Cell membrane fatty acids in colonic mucosa and colorectal tumours were determined by gas liquid chromatography. Animals fed the $20 \%$ fat diet developed more carcinomas ( 28 cancers in 14 rats) than those fed the $5 \%$ fat diet (14 cancers in 15 rats; $\chi^{2}=8 \cdot 03$, $\mathbf{p}=0.0046)$ but they did not develop significantly more adenomas ( 28 and 24 respectively). Cell membrane fatty acid analysis showed a considerable increase in the content of arachidonic acid (20:4, $n-6)$ in the tumours (mean (SEM) $11.7(1.5) \%)$ compared with colonic mucosa $(4 \cdot 2(0.4) \% ; p<0.05)$. Dietary fatty acid composition was also found to influence the profile of fatty acids in the colonic mucosa. This study suggests that a high saturated fat diet promotes the malignant transformation of colorectal adenomas. The colorectal tumours were characterised by an increased cell membrane arachidonic acid, the precursor of putative cancer promoting prostaglandins.
\end{abstract}

The relation between dietary fat and colorectal cancer is not fully understood. Evidence from epidemiological studies suggests that a high intake of saturated fat is associated with colorectal carcinogenesis. ${ }^{12}$ This finding has been supported by experimental studies using rodent models. These show that high saturated fat diets strongly promote the development of colorectal tumours that have been initiated by chemical carcinogens. ${ }^{34}$

How dietary lipids promote cancer is not clearly known. Although much of the research has centred on the possible indirect effects of dietary fats, such as that on faecal bile acids, ${ }^{5}$ more direct mechanisms have received little attention. ${ }^{4}$ Thus, exogenous fatty acids may result in changes in the fatty acid profile of colonic mucosal cell membranes. ${ }^{6}$ Exogenous fatty acids may cause a variety of important structural and. functional changes such as fluidity ${ }^{67}$ permeability, ${ }^{8}$ carrier mediated transport, ${ }^{9}$ increased exposure of membrane proteins, ${ }^{10}$ receptor mobility, ${ }^{11}$ and receptor binding. ${ }^{12}$ In vitro, increased malignancy may be related to increased membrane fluidity, increased unsaturated fatty acid content, and increased values of phosphatidyl inositol. ${ }^{13}$ Surprisingly, there have been no studies on colonic mucosal cell membrane fatty acids in either human or experimental colorectal carcinogenesis. In a study in which a 5\% saturated fat diet was given as the ethyl ester of stearic acid, Sakaguchi et $a l^{14}$ were unable to show any significant changes between azoxymethane induced colorectal tumours and unaffected mucosa, but only total lipid extraction was employed in this work.

We therefore undertook the present experimental colorectal tumour study in which cell membranes of tumours and mucosa were prepared for fatty acid analysis and compared the findings of a $20 \%$ saturated fat diet, which has been shown to be tumour promoting, to those of a 5\% saturated fat diet. ${ }^{34}$

\section{Methods}

EXPERIMENTAL DESIGN

Eighty six weanling male Wistar rats weighing 50-75 g were supplied by Harlan OLAC Limited (Oxford, UK). After a one week period of acclimatisation, the 5 week old rats were divided into two experimental groups to receive either a $5 \%$ saturated fat diet or a $20 \%$ saturated fat diet. The diets containing $5 \%$ and $20 \%$ saturated fat as beef suet were prepared by Special Diet Services (SDS) Limited, Witham, Essex. The composition of the basal diet used to constitute the two types of diet are shown in Table I. The relative proportions of the major fatty acids in these two diets are shown in Figure 1. The fatty acid composition of the two diets differed in only one important respect - there was more linoleic acid $(18: 2, n-6)$ in the $5 \%$ fat diet $(12 \% v 5 \%)$. This difference was deliberate. We wanted to ensure that there was sufficient dietary intake of linoleate as this is an essential fatty acid which, if deficient, would have seriously affected the animals in this group. The total calorific value of the $5 \%$ fat diet was $12 \mathrm{MJ} / \mathrm{kg}$ and that for the $20 \%$ fat diet was $15 \mathrm{MJ} / \mathrm{kg}$.

Animals were housed in the Biomedical Services Unit, Leicester University; four to a cage with diets and water being given freely. The rats were observed daily and weighed weekly. For each group of 43 rats being fed a special diet, 33 were treated with the carcinogen, azoxymethane, which was injected intraperitoneally in a dose of $15 \mathrm{mg} / \mathrm{kg}$ once a week for six weeks. The remaining 10 rats in each dietary group acted as controls for that group and were injected with an equal volume of carrier solution ( $0.9 \%$ saline) weekly for six weeks.

The 33 azoxymethane treated rats in each dietary group were further subdivided into two 
TABLE I Composition of the basal diet used in the animal studies

\begin{tabular}{lr}
\hline Weight & $100.000 \mathrm{~g}$ \\
Moisture & $0.363 \mathrm{~g}$ \\
Crude fat & $0.300 \mathrm{~g}$ \\
Crude protein & $12.979 \mathrm{~g}$ \\
Crude fibre & $10.095 \mathrm{~g}$ \\
Ash & $5.973 \mathrm{~g}$ \\
Total dietary & $11.420 \mathrm{~g}$ \\
fibre & \\
Starch & $30.945 \mathrm{~g}$ \\
Sugar & $32.101 \mathrm{~g}$ \\
Calcium & $0.828 \mathrm{mg}$ \\
Phosphate & $0.639 \mathrm{mg}$ \\
Sodium & $0.320 \mathrm{mg}$ \\
Chloride & $0.428 \mathrm{mg}$ \\
Magnesium & $0.170 \mathrm{mg}$ \\
Potassium & $0.977 \mathrm{mg}$ \\
Lysine & $0.780 \mathrm{mg}$ \\
Iron & $0.080 \mathrm{mg}$ \\
Copper & $0.016 \mathrm{mg}$ \\
Manganese & $0.055 \mathrm{mg}$ \\
Zinc & $0.047 \mathrm{mg}$ \\
Cobalt & $0.527 \mathrm{mg}$ \\
Selenium & $0.068 \mathrm{mg}$ \\
Retinol & $1.527 \mathrm{mg}$ \\
Calciferol & $0.026 \mathrm{mg}$ \\
Tocopherol & $0.047 \mathrm{mg}$ \\
Vitamin B1 & $9.800 \mathrm{mg}$ \\
B2 & $11.000 \mathrm{mg}$ \\
B6 & $6.900 \mathrm{mg}$ \\
B12 & $5.650 \mathrm{mg}$ \\
Folic acid & $2.060 \mathrm{mg}$ \\
Niacin & $33.500 \mathrm{mg}$ \\
Pantethenic acid & $17.750 \mathrm{mg}$ \\
Choline & $0.405 \mathrm{mg}$ \\
Inositol & $0.450 \mathrm{mg}$ \\
Biotin & $0.125 \mathrm{mg}$ \\
\hline & \\
\hline &
\end{tabular}

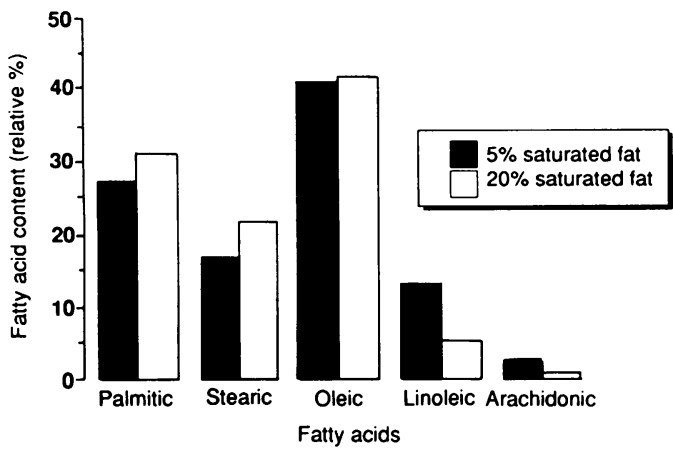

Figure 1: Fatty acid composition of the two saturated fat diets.

groups. Fifteen animals were killed 15 weeks after the last injection of carcinogen for histological analysis of colorectal tumours. The colon and rectum from each animal were fixed in a $10 \%$ formalin solution overnight. Tumours were excised and individually processed for histological analysis (see below).

The remaining 18 carcinogen treated rats and 10 saline treated control rats from each dietary group were killed 20 weeks after the last injection of carcinogen or carrier solution. These animals were given an additional five weeks to allow further growth of any colorectal tumours and thus to increase the yield of tissue for cell membrane fatty acid analysis (see below). The whole colon and rectum were removed, all macroscopic tumours were carefully excised, and the tumours from each colon were pooled for fatty acid analysis. The remaining colonic mucosa was then separated from the underlying muscle layers by drawing a clean glass microscope slide along the length of the colon under pressure.

During the 17th week of the experiment (age of animals $=23$ weeks), food consumption studies were performed on eight rats selected at random from each dietary group. Each animal was housed separately. After acclimatisation for two days the exact daily dietary consumption was determined over the subsequent four days.

\section{HISTOLOGICAL ANALYSIS}

All the histological material generated by the study was examined by one consultant pathologist (ICT) who was unaware of the experimental group from which specimens were taken.

At necropsy the entire colon and rectum were removed. This procedure was facilitated by division of the pubic symphysis, enabling complete excision of the rectum and anus. The bowel was opened longitudinally, cleaned with normal saline, and pinned out on a cork board. It was measured from the proximal caecum to the anal verge. The sites of any tumours were measured from the proximal caecum and distances were standardised as percentages of the length of the bowel wall. Extracolonic neoplasms were carefully sought and biopsy samples were taken. The liver was histologically processed in search of any metastases.

After fixation of the colon and rectum in $10 \%$ formalin, tumours were excised and processed individually. The specimens were embedded in paraffin wax, cut into $4 \mu \mathrm{m}$ thick sections, and stained with haemoxylin and eosin. All the slides were coded, and the code was broken only after all the specimens had been examined. The maximum size of each tumour was measured and the tumours were categorised into adenomas or carcinomas.

Adenomas were classified as tubular, villous, or tubulo-villous type. Dysplasia was also recorded as mild, moderate, or severe.

Carcinomas were staged as follows: stage $\mathrm{Al}=$ carcinoma invading no deeper than the submucosal layer; stage $\mathrm{A} 2=$ carcinoma invading the muscularis layers but not beyond the bowel wall; stage $B=$ invasion of carcinoma through the wall. The carcinomas were also graded histologically: grade $1=$ well differentiated; grade $2=$ moderately well differentiated; grade $3=$ poorly differentiated.

\section{ANALYTICAL PROCEDURES}

Cell membranes were prepared from colonic mucosa and tumours using an adaptation of the methods of van Blitterswijk $e t a l{ }^{15}$ and Standring and Williams. ${ }^{16}$ In brief, after homogenisation, cellular organelles were discarded subsequent to centrifugal separation at $70000 \mathrm{~g}$ for one hour using a fixed angle rotor (Centikon). The crude membranes were then purified by density centrifugation at $110000 \mathrm{~g}$ for 15 hours and washed in $\mathrm{NaCl}$-Tris $\mathrm{HCl}$ buffer at $70000 \mathrm{~g}$ for one hour. Fatty acids were extracted from cell membranes using the method of Bligh and Dyer,${ }^{17}$ and were further purified using silica Sep-Pak cartridges (Waters Associates, Milford, Mass, USA). Saponification and methyl esterification was undertaken using the methods of Alexander et al. . $^{18}$

The fatty acid methyl esters were identified and quantified by gas liquid chromatography (GLC), using a Perkin-Elmer F17 chromatograph fitted with an on column injector and a flame ionisation detector. The column used was a $3.6 \mathrm{~mm}$ diameter stainless steel type, packed with $15 \%$ CP-Sil 84 on Chromosorb W HP (100 120 mesh, supplied by Chrompack, UK). The analytical conditions were as follows; carrier gas supply pressure $100 \mathrm{kNm}^{-2}$, inlet pressure 140 $\mathrm{kNm}^{-2}$, injection port temperature $250^{\circ} \mathrm{C}$. The GLC was interfaced with a Shimadzu integrator

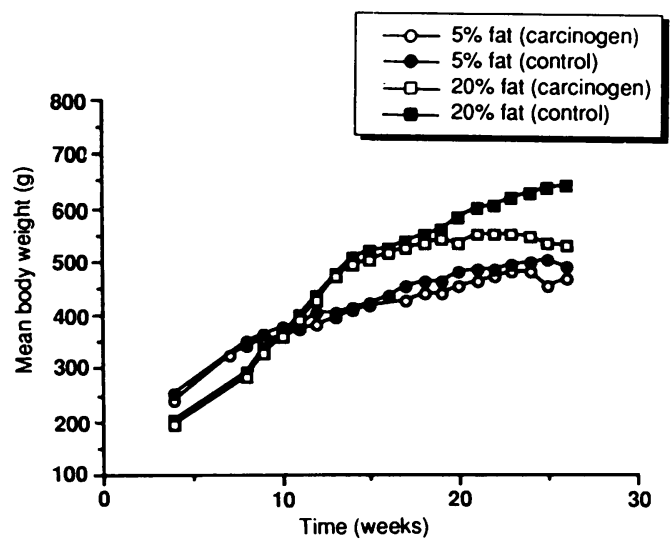

Figure 2: Body weight of carcinogen and control treated animals against time. 


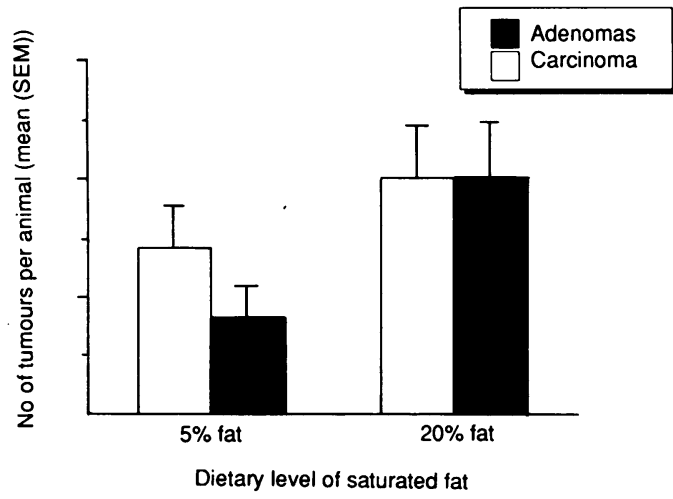

Figure 3: Tumour yields in the two dietary groups.

which was programmed to measure the area under each peak. Injection of $2 \mu \mathrm{l}$ samples was by means of a $5 \mu \mathrm{l}$ microsyringe fitted with a silica quartz needle. After injection the sample was allowed to run for approximately 45 minutes.

Fatty acid methyl esters were identified by comparing their retention times with those of authentic standards (Sigma UK Ltd, Poole, Dorset). The major fatty acids detectable using this system were palmitic acid (16:0), stearic acid (18:0), oleic acid (18: $1, n-9)$, linoleic acid $(18: 2, n-6)$, and arachidonic acid $(20: 4, n-6)$. Several other minor fatty acids could be detected in some samples but as their separation and quantification could not be reliably reproduced, they were not considered in the further analysis. The area under the peak of each fatty acid was expressed as a proportional value of the total area of all the major fatty acids (\%) and was the mean of at least two traces.

\section{STATISTICAL ANALYSIS}

All data were entered into the University of Leicester mainframe computer and analysed using the Minitab statistics programme. Categorical variables were analysed by the $\chi^{2}$ test. Continuous variables were analysed by the two tailed Mann-Whitney U test for pairs of groups and for multiple groups by analysis of variance using the Wilk's criterion. ${ }^{19}$ The significances of $\chi^{2}$ and the $F$ ratio were determined by reference to published tables (Documenta Geigy).

\section{Results}

\section{DIETARY CONSUMPTION AND WEIGHT GAIN}

The mean (range) consumption of food for those animals on the $5 \%$ fat diet who had received azoxymethane was $28 \cdot 1(20-50) \mathrm{g} /$ day and for control animals this was $39 \cdot 9(20-50) \mathrm{g} /$ day. The respective figures for rats on the $20 \%$ fat diet were $20.9(5-35) \mathrm{g} /$ day and $22.5(10-35) \mathrm{g} /$ day. Food consumption was significantly less in the control group on the $20 \%$ diet compared with the control group on the $5 \%$ diet $(p<0.05)$. None of the other paired groups showed significant differences in food consumption, in particular the comparison of azoxymethane treated animals on either diet.

Animals' weights over the course of the experiment are shown in Figure 2. Control animals tended to gain more weight than azoxymethane treated animals but the only significant difference was in the control group receiving the $5 \%$ diet $(\mathrm{p}<0.05)$.

\section{HISTOLOGICAL RESULTS}

Naked eye and microscopic examination of the rat colorectums showed a range of benign and malignant colorectal neoplasms with histological features similar to humans. In animals on the $5 \%$ fat diet there were totals of 24 colonic adenomas and 12 colonic adenocarcinomas in the 14 azoxymethane treated rats. Similarly, for the 15 azoxymethane treated animals on the $20 \%$ fat diet there were 28 adenomas and 28 adenocarcinomas. None of the control animals had tumours. The difference in the number of adenocarcinomas was significant $\left(\chi^{2}=8.03\right.$, $\mathrm{p}=0.0046$ ); the data, expressed as the mean number of tumours per animal, are shown in Figure 3.

Detailed histological analysis of the adenomas showed 23 of the tubular type from the $5 \%$ fat diet group compared with 27 from the $20 \%$ fat diet group (not significant; NS). There was one tumour of the tubulovillous type in each group and there were no tumours of the pure villous variety. The mean (SEM) size of adenomas was $3.5(0.5) \mathrm{mm}$ (range $1-13 \mathrm{~mm}$ ) in the $5 \%$ fat diet group compared with $3.0(0 \cdot 3) \mathrm{mm}$ (range 1-8 $\mathrm{mm}$ ) in the $20 \%$ fat diet group (NS). Severe dysplasia was present in $12(50 \%)$ of the adenomas from the $5 \%$ fat diet group compared with only $3(12 \%)$ from the $20 \%$ fat diet group $\left(\chi_{1}^{2}=9 \cdot 717, \mathrm{p}<0.002\right)$. Only $3(13 \%)$ of the 24 adenomas from the $5 \%$ fat diet group had adenomas in the proximal half of the colorectum compared with $36 \%$ of the 28 adenomas from the $20 \%$ fat group but this was not statistically significant $\left(\chi_{1}^{2}\right.$ with Yates's correction $=2 \cdot 58$ ).

Details of histological analysis of carcinomas of the two dietary groups is shown in Table II; none of the differences were statistically significant. Three $(25 \%)$ of the carcinomas in the $5 \%$ fat diet group were in the proximal half of the colorectum compared with $10(36 \%)$ of the carcinomas in the $20 \%$ fat diet group (NS).

Combining adenomas and carcinomas together, there were $6(16 \cdot 7 \%)$ of 36 tumours in the proximal half of the colorectum from the $5 \%$ fat diet group compared with $20(35.7 \%)$ of 56 tumours from the $20 \%$ fat diet group $\left(\chi_{1}^{2}=3.921\right.$, $\mathrm{p}=0.0478$.

TABLE II Details of histological analysis of carcinomas in the two dietary fat groups

\begin{tabular}{lll}
\hline & \multicolumn{2}{c}{ Dietary group } \\
\cline { 2 - 3 } $\begin{array}{l}\text { Histological } \\
\text { parameter }\end{array}$ & $\begin{array}{l}5 \% \text { fat } \\
\text { (carcinomas }=12)\end{array}$ & $\begin{array}{l}20 \% \text { fat } \\
\text { (carcinomas }=28)\end{array}$ \\
\hline Stage: & & \\
A1 & $9(75 \%)$ & $25(89 \%)$ \\
A2 & $2(17 \%)$ & $2(7 \%)$ \\
B & $1(8 \%)$ & $1(4 \%)$ \\
Grade: & 0 & $3(11 \%)$ \\
1 & $10(83 \%)$ & $18(64 \%)$ \\
2 & $2(16 \%)$ & $7(25 \%)$ \\
3 & $4 \cdot 3(0 \cdot 5)$ & $4 \cdot 4(0 \cdot 3)$ \\
Size (mm): & $2-8$ & $2-8$ \\
Mean (SEM) & Range & \\
\hline
\end{tabular}

Other than the incidence of carcinomas between the two groups, none of the differences were statistically significant. 


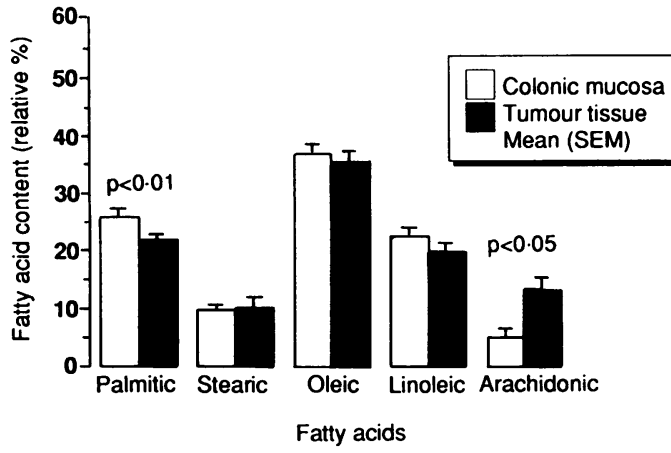

Figure 4: Cell membrane fatty acid profiles of colonic mucosa and tumours in rats fed $5 \%$ saturated fat diet.

Peritoneal carcinomatosis was seen in one animal from each dietary group. Only one animal, from the $20 \%$ fat diet group, had hepatic metastases.

\section{FATTY ACID ANALYSIS}

The fatty acid content of non-malignant colonic mucosa and colonic tumour tissues from carcinogen treated animals in each of the dietary groups is shown in Figures 4 and 5. There was a significantly higher proportion of arachidonic acid in tumour cell membranes when compared with cell membranes isolated from the surrounding non-malignant colonic mucosa of animals fed both the $5 \%$ fat diet $(p<0.05)$ and the $20 \%$ fat diet $(p<0.05)$. As would be anticipated by the relatively increased linoleate in the $5 \%$ fat diet group, there was significantly more present in both tumours and mucosa in this group compared with the $20 \%$ fat diet group $(\mathrm{p}<0.001)$. The proportional values of arachidonate in the tumours compared with mucosa were almost identical in the two dietary groups (mean (SEM) $11.7(1.5) \% v 4 \cdot 2(0.4) \%$. The higher tumour arachidonic acid value was balanced by lower proportions of palmitic acid in the $5 \%$ fat diet group and oleic acid in the $20 \%$ fat diet group. A summary of the findings of the multivariate analysis is given in Table III. This shows that the carcinogen per se had no effect on the fatty acid profile of colonic mucosa or tumours. The level of dietary fat intake was shown to have a significant influence on cell membrane fatty acid profiles. The level of dietary linoleic acid was proportionately higher in the 5\% fat diet (Fig 1) and this was correlated with higher linoleic acid values in colonic mucosa and tumours in this

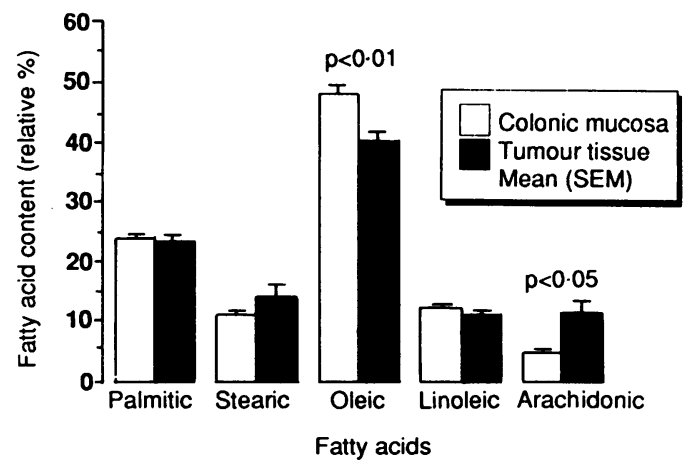

Figure 5: Cell membrane fatty acid profiles of colonic mucosa and tumours in rats fed $20 \%$ saturated fat diet.
TABLE III Factors influencing the membrane fatty acid profiles of colonic mucosa and colonic tumours

\begin{tabular}{lcl}
\hline Variable & F ratio & p value \\
\hline $\begin{array}{l}\text { Treatment } \\
\text { (carcinogen } v \text { control) }\end{array}$ & 1.2 & $0.33(\mathrm{NS})$ \\
$\begin{array}{l}\text { Amount of dietary fat } \\
\quad(5 \% v 20 \%)\end{array}$ & 18.8 & $<0.0001$ \\
$\begin{array}{c}\text { Tisue } \\
\text { (mucosa } v \text { tumour) }\end{array}$ & 48.1 & $<0.0001$ \\
\hline
\end{tabular}

F ratios quoted were calculated using the Wilk's criterion. NS=not significant.

group compared with the $20 \%$ fat diet group (compare Figs 4 and 5). The analysis also showed significant differences in the overall fatty acid profiles of cell membranes from malignant and non-malignant colonic mucosa, this effect being due to increased arachidonic acid in the tumours of both groups.

\section{Discussion}

Analysis of the tumour yield showed that a higher saturated fat diet was associated with greater colorectal tumour promotion than a low fat diet. This finding is consistent with work from other groups, which has been reviewed previously. The analysis of tumour cell membrane fatty acid composition showed consistently high values of arachidonic acid in colorectal tumour tissue when compared with the surrounding nonmalignant colonic mucosa. This contrasts with the results of Sakaguchi et al, who found no excess of arachidonate. These authors, however, looked only at total lipid extraction. ${ }^{14}$ In the present study, we undertook exacting separation of cell membranes, the main site for fatty acid substrates involved in important biotransformation processes. This study showed for the first time significantly increased concentrations of cell membrane related arachidonic acid in colorectal tumours. Moreover, we have recently shown a small but significant excess of arachidonate in human colorectal cancers compared with mucosa. ${ }^{20}$

A major metabolic role of arachidonic acid is its biotransformation to the series 2 prostaglandins These substances have very short half lives and therefore are synthesised locally from arachidonic acid which is released from cell membrane phospholipids by phospholipases. Evidence suggests that certain prostaglandins are involved in certain types of carcinogenesis. ${ }^{21-23}$ Minoura et $a l^{24}$ have shown increased prostaglandin $\mathrm{E}_{2}$ values in experimental colorectal tumours relative to the surrounding nonmalignant colonic mucosa. While human colonic cancers were shown to produce prostaglandins in a limited study, ${ }^{25}$ the clinical relevance of this remains to be realised. It is perhaps important that inhibitors of arachidonic acid metabolism such as indomethacin ${ }^{26}$ and polyunsaturated fatty acids of the N-3 series ${ }^{2+27}$ are potent inhibitors of chemically induced colorectal cancers and also of transplanted human colonic cell lines. ${ }^{28}$

It is important to appreciate that while dietary content affected the cell membrane fatty acid profile of the mucosa and the tumours, this was quite distinct from the tumour effect itself. The effect of diet was to raise the proportion of 
linoleic acid in direct proportion to that available in the diet. In contrast, there was no direct lipid altering effect by azoxymethane; changes in fatty acid composition were as a consequence of the induction of tumours, viz an increase in the concentration of arachidonic acid. This effect was quite independent of dietary values. It is this observation that is of considerable importance in understanding the underlying biochemical behaviour of colorectal tumours. A number of previous studies have been severely criticised ${ }^{29}$ because animals who received the proportionally lower fat diets have had an identical fatty acid profile resulting in essential fatty acid deficiency that might affect not only animal growth but, more importantly, tumour growth or promotion. ${ }^{30}$ This we were careful to avoid. Adenomas and adenocarcinomas were not analysed separately for fatty acids because of the difficulties in obtaining sufficient tissue for both accurate histological analysis and eell membrane examination with subsequent fatty acid examination and analysis. Any major differences in fatty acids between adenomas and adenocarcinomas should perhaps have been detected in a comparison of the tumours between the two groups; there was virtually none. We would therefore surmise that increased arachidonate is a feature of neoplasia rather than malignancy per se. Further investigations are required to clarify this point.

Although the recent discoveries relating to arachidonate and prostaglandins may point to new therapeutic approaches in human colorectal cancer, there is another feature of this study which is perhaps of equal importance. While a number of experiments have shown a tumourpromoting effect of increased saturated fat, ${ }^{231-34} \mathrm{a}$ distinction has not often been made between benign and malignant tumours. ${ }^{23132}$ This study has clearly shown an increased number of adenocarcinomas in the $20 \%$ saturated fat diet group, associated with an increased number of tumours in the proximal as well as distal colorectum. While there was little to distinguish the histological parameters of the cancers between the two groups, the adenomas from the $5 \%$ fat diet group had a much greater incidence of severe dysplasia. Thus, a $20 \%$ saturated fat diet does not promote uniformly the sequence from normal mucosa through mild, moderate, and severe dysplasia to carcinoma ${ }^{35}$; it seems that only the last sequence is promoted. Again further work is required to confirm this observation.

In some experimental cancers there is evidence to suggest that a high caloric diet enhances tumour growth. ${ }^{44}$ Whether this pertains to the present study is not certain but seems unlikely. While the high fat diet had a higher energy value $(15 \mathrm{MJ} / \mathrm{kg} v 12 \mathrm{MJ} / \mathrm{kg}$ ), consumption of food was greater with the low fat diet. Moreover, the calculated caloric intake (in animals aged 23 weeks) was $1.0 \mathrm{MJ} / \mathrm{kg} /$ day for control animals on the low fat diet compared with $0.6 \mathrm{MJ} / \mathrm{kg} /$ day for control animals on the high fat diet. Despite the apparent higher caloric intake, animals on the low fat diet gained less weight, an observation consistent with previous studies. ${ }^{36}$ In our experiments this might be explained by the relative proportion of linoleic acid in the two diets $(12 \%$ in the low fat diet and 5\% in the high fat diet), as this suppresses the lipogenic effect of dietary carbohydrates. ${ }^{37}$ Finally, there were no significant differences for either food consumption or weight gain between the two dietary groups that received azoxymethane.

Thus, it seems that the greater proportion of cancers developing in the high saturated fat dietary group is not directly related to caloric intake. Lipid metabolism in cancer patients undergoes subtle and ill defined alterations. ${ }^{38} \mathrm{~A}$ long term high saturated fat diet raises the concentrations of serum lipids and the peripheral activity of lipoprotein lipase. ${ }^{39}$ Moreover, increased low density lipoprotein receptor activity is a feature of growing cells and some malignancies. ${ }^{40}$ Whether this process is also involved in driving the development of benign to malignant cancers remains to be determined.

We are extremely grateful for a generous grant from the Trent Regional Health Authority that fully funded this project and which included the support of Mrs H A Clayton, MPhil.

Based on a paper presented to the Surgical Research Society, July 1989 and published as an abstract: BrF Surg 1989; 76: 1337.

1 Drasar BS, Irving D. Environmental factors and cancer of the colon and breast. Brf Cancer 1973; 27: 168-72.

2 Armstrong B, Doll R. Environmental factors and cancer incidence and mortality in different countries with special reference to dietary practices. Int 7 Cancer 1975; 15: 617-31.

3 Nigro ND, Singh DV, Campbell RL, Pak MS. Effect of dietary beef fat on intestinal tumour formation by azoxymethane in rats. $7 N C I 1975 ; 54: 439-42$.

4 Nicholson ML, Neoptolemos JP, Clayton HA, Heagerty AM. Diet and colorectal cancer. Int Clin Nutr Rev 1988; 8: 18097.

5 Sakaguchi M, Minoura T, Hiramatsu Y, et al. Effects of dietary saturated and unsaturated fatty acids on fecal bile acids and colon carcinogenesis induced by azoxymethane in rats. Cancer Res 1986; 46: 61-5.

6 Brasitus TA, Davidson ND, Schacter D. Variations in dietary triacylglycerol saturation alter the lipid composition and fluidity of rat intestinal plasma membranes. Biochim Biophys Acta 1985; 812: 460-72.

7 Stubbs CD, Smith AD. The modification of mammalian polyunsaturated fatty acid competition in relation to mempolyunsaturated fatty acid competition in relation to mem89-137.

8 Sanderman $H$. Regulation of membrane enzymes by lipids. Biochim Biophys Acta 1978; 515: 209-37.

9 Burns CP, North JAB. Adriamycin transport and sensitivity in fatty acid-modified leukemic cells. Biochim Biophys Acta 1986; 888: 10-17

10 Shinitzky M, Rivnay B. Degree of exposure of membrane proteins determined by fluorescence quenching. Biochemistry $1977 ; 16$ : $982-6$.

11 Horwitz AF, Hatten ME, Burger MM. Membrane fatty acid replacements and their effect on growth and lectin-induced

12 Biswas R, Basu M, Sen-Majumdar R, Das M. Intrapeptide auto-phosphorylation of the epidermal growth factor receptor. Regulation of kinase catalytic function by receptor dimerization. Biochemistry 1985; 24: 3795-802.

13 Haeffner EW, Heck B, Kolbe K. Difference in plasma membrane structure between two sublines of Ehrlich-Lettre ascites tumor cells. Biochim Biophys Acta 1982; 693: 280-6.

14 Sakaguchi M, Kiramatsu Y, Takada H, et al. Effect of dietary unsaturated and saturated fats on azoxymethane-induced colon carcinogenesis in rats. Cancer Res 1984; 44: 1472-7.

15 van Blitterswijk WL Emmelot P Peltkamp CA Studies on plasma membranes. XIX. Isolation and characterisation of plasma membrane fraction from calf thymocytes. Biochim Biophys Acta 1973; 298: 577-92.

16 Standring R, Williams AF. Glycoproteins and antigens of membranes prepared from rat thymocytes after lysis by shearing or with the det

17 Bligh EC, Dyer WJ. A rapid method of total lipid extraction and purification. Can f Biochem Physiol 1959; 37: 111-15.

18 Alexander LR, Justice JB, Madden J. Fatty acid composition of human erythrocyte membranes by capillary gas chromatography-mass spectrometry. $\mathcal{f}$ Chromatography 1985; 342: 1-12.

19 Aitchison J. The statistical analysis of compositional data. $f$ Roy Stat Soc 1982; B44: 138-77.

20 Imray C, Husband D, Rowley S, Lawson N, Neoptolemos JP. Arachidonic acid and docosahexaenoic acid are increased in
human colorectal cancer. [Abstract.] Gut 1990; 31: A605.

21 Lynch NR, Castes M, Astoin M, Salomon JC Mechanism of inhibition of tumour growth by aspirin and indomethacin. Br7 Cancer 1978; 38: 503-12. 
22 Pollard M, Luckert PH. Effect of indomethacin on intestina tumors induced in rats by the acetate derivative of dimethylnitrosamine. Science 1981; 214: 558-9.

23 Goodwin JS, Ceuppens J. Regulation of the immune response by prostaglandins. F Clin Immunol 1983; 3: 295-315.

24 Minoura T, Takata T, Sakaguchi M, et al. Effect of dietary eicosapentaenoic acid on azoxymethane-induced colon carcinogenesis in rats. Cancer Res 1988; 48: 4790-4.

25 Bennett A, Del Tacca M, Stamford IF, Zebro T. Prostaglandins extracted from tumours of human large bowel. $\mathrm{Br} \mathcal{F}$ Cancer 1977; 35: 881-4.

26 Narisawa T, Sako M, Sano M, et al. Prevention of colon polyposis and carcinomas by indomethacin in animal models. Cancer 1985; 56: 1719-24.

27 Reddy BS, Sugie S. Effect of different levels of omega-3 and omega- 6 fatty acids on azoxymethane-induced colon carcinogenesis in F344 rats. Cancer Res 1988; 48: 6642-7.

28 Sakaguchi M, Rowley S, Kane N, et al. Modulation of colon cancer fatty acids by dietary N-3 lipids results in tumour growth suppression. [Abstract.] Br f Surg 1989; 76: 1337.

29 Vergroesen AJ. Introduction. In: Vergroesen AJ, Crawford M eds. The role of fats in human nutrition. 2 nd ed. London: Academic Press, 1989: 1-44.

30 Smedley-Maclean I, Nunn LCA. Fat-deficiency disease of rats. The relation of the essential unsaturated acids to tumour formation of the albino rat in normal diet. Biochem $\mathcal{F}$ 1941; 35: 983-9. 31 Reddy BS, Narisawa T, Maranpot R, Weisburger $\mathrm{JH}, \mathrm{Wynder}$
EL. Animal models for the study of dietary factors and cancer of the large bowel. Cancer Res 1975; 35: 3421-6.
32 Bull AW, Soullier BK, Wilson PS, Hayden MT, Nigro ND. Promotion of azoxymethane-induced intestinal cancer by high-fat diet in rats. Cancer Res 1979; 39: 4956-9.

33 Reddy BS, Watanabe K, Weisburger JH. Effect of high-fa diet on colon carcinogenesis in F344 rats treated with 1,2 dimethylhydrazine, methylazoxymethanol acetate methylnitrosourea. Cancer Res 1977; 37: 4156-9.

34 Kritchevsky D, Weber MM, Klurfield DM. Dietary fat versus caloric content in initiation and promotion of 7,12 caloric content in initiation and promotion of 7,12dimethylbenz(a)antracene induced mam
genesis in rats. Cancer Res 1984; 44: 3174-7.

35 Morson BC. Evolution of $1984 ; 44: 3174-7$. Morson BC. Evolution of

36 Reddy BS, Maeura Y. Tumor promotion by dietary fat in azoxymethane-induced colon carcinogenesis in female $\mathrm{F} 34$ rats: influence of amount and source of dietary fat. $\mathfrak{F N C I}$ 1984; 72: 745-50.

37 Jeffcoat R, Roberts PA, James AT. The control of lipogenesis by dietary linoleic acid and its influence on the deposition of fat. Eur f Biochem 1979; 101: 447-53.

38 Neoptolemos JP, Clayton H, Heagerty AM, et al. Dietary fat in relation to fatty acid composition of red cells and adipose relation to fatty acid composition of red cells and adipose

39 Goldstein JL, Brown MS. The low-density lipoprotein pathway and its relation to atherosclerosis. Ann Rev Biochem 1977; 46: 897-930.

40 Vitols S, Gohorton G, Ost A, Peterson CD. Hypocholesterolaemia in malignancy due to elevated low-densitylipoprotein-receptor activity in tumour cells: evidence from studies in leukaemic patients. Lancet 1985; ii: 1150-4. 